\title{
Pengaruh Koefisien Gesek Terhadap Tegangan Fiber Optik dalam Akrilik Menggunakan Metode Elemen Hingga
}

\author{
Ojo Kurdi ${ }^{\mathrm{a}, ~}{ }^{\text {, }}$, Gunawan Dwi Haryadi ${ }^{\mathrm{a}}$, Aulia Rahman ${ }^{\mathrm{a}}$, Ian Yulianti ${ }^{\mathrm{b}}$ \\ ${ }^{a}$ Departemen Teknik Mesin Fakultas Teknik, Universitas Diponegoro \\ Jalan Prof Sudharto, Tembalang, Semarang, Central Java, Indonesia \\ burusan Fisika, Universitas Negeri Semarang \\ Sekaran Campus, Gunung Pati, Semarang, Central Java, Indonesia \\ *E-mail: ojokurdi@ft.undip.ac.id
}

\begin{abstract}
Nowadays, acrylic is commonly used as wall and roof materials. Optical fiber is usually embedded in wall and roof material as temperature and strain sensor. This paper presents investigation of the effect of friction coefficient to stress inside optical fiber that is embedded in acrylic. The simulation was done by implementing Finite Element Method using ABAQUS software. Contact between acrylic and optical fiber was modelled as frictionless and with friction. The friction coefficient was varied for various values which are 0.3, 0.5 and 0.8. The results show that the highest stress is $39.49 \mathrm{MPa}$ for 0.8 friction coefficient and the lowest stress is $37.33 \mathrm{MPa}$ for frictionless condition. It can be concluded that the higher the friction coefficient the higher von Misses stress in fiber optic and the lower von Misses stress in acrylic.
\end{abstract}

Key words: acrylic, finite element method, friction coefficient, fiber optic, von Misses stress

\section{Abstrak}

Saat ini akrilik banyak digunakan sebagai bahan dinding dan atap dan untuk keperluan sensor suhu dan tekanan maka serat optik ditanam dalam bahan bangunan tersebut. Simulasi dilakukan dengan menggunakan Metode Elemen Hingga (MEH) dengan menggunakan perangkat lunak komersial ABAQUS. Kontak antara serat optic dan akrilik dimodelkan dengan keadaan tanpa gesekan (frictionless) dan dengan adanya gesekan dengan koefisien gesek tertentu. Kofisien gesek divariasikan sebesar 0,3, 0,5 dan 0,8. Hasil simulasi menunjukkan bahwa tegangan von Misses terbesar adalah sebesar 39,49 MPa untuk koefisien gesek 0,8 dan tegangan von Misses terendah adalah sebesar 37,33 MPa untuk keadaan tanpa gesekan. Maka dapat disimpulkan bahwa semakin tinggi koefisien gesek tegangan von Misses pada akrilik akan semakin rendah dan tegangan von Misses pada serat optic akan semakin tinggi.

Kata kunci: akrilik, metode elemen hingga, koefisien gesek, serat optic, tegangan von Misses

\section{Pendahuluan}

Serat optik merupakan salah satu media transmisi komunikasi optik yang cukup handal. Pemakaiannya telah meluas di berbagai bidang termasuk telekomunikasi, instumentasi medis dan transmisi data. Ini karena serat optik plastik mempunyai beberapa kelebihan yang tidak dimiliki oleh media transmisi yang lain, di antaranya adalah bandwidthnya yang sangat lebar, ukurannya kecil serta bobotnya ringan, mempunyai derajat isolasi yang tinggi, bebas dari interferensi elektromagnetik (EMI), tidak mengalirkan arus sehingga tidak akan terjadi ledakan maupun percikan api, tidak berkorosi, memiliki tingkat numeris (Numerical Apature, NA) yang besar sehingga kemampuan untuk mengumpulkan energi cahaya tinggi.

Perkembangan fiber optik yang pesat menyebabkan aplikasi fiber optik saat ini tidak hanya dimanfaatkan sebagai media transmisi tetapi juga sebagai sensor. Sensor regangan dan tegangan menggunakan fiber optik memiliki kelebihan dibandingkan dengan sensor lain karena fiber optik itu sendiri unggul dalam ukuran yang kecil, tahan terhadap interferensi elektromagnetik dan radiasi cahaya serta tidak terpengaruh pada sifat bahan sehingga dapat dilekatkan dengan bahan komposit secara non-obstrusive.

Dalam pemakaiannya serat optik banyak ditanam didalam dinding, di dalam atap dan lain lain material. Akrilik sekarang sudah banyak digunakan sebagai material dasar atap, dinding dan lain lain, sehingga untuk mengetahui kekuatan serat optic yang digunakan sebagai sensor tekanan atau temperatur perlu dilakukan analisa tegangan serat optic yang ditanam didalam akrilik. Hal ini dimaksudkan untuk mengetahui tekanan dan temperautrartur maksimal yang bisa diterima oleh akrilik dalam keadaan aman. Penelitian ini dilakukan dengan menggunakan Metode Elemen Hingga $(\mathrm{MEH})$. Metode ini memiliki banyak keunggulan, terutamanya MEH dapat menghemat biaya, karena dalam metode ini untuk menganalisa tegangan suatu benda dapat dilakukan hanya dengan membuat simulasi dalam komputer, dengan bantuan perangkat lunak, tanpa harus membuat prototipe aslinya. 
Banyak peneliti yang telah melakukan penelitian tentang analisa tegangan pada serat optic yang ditananm di dalam material tertentu, seperti dalam komposit, dalam prakteknya metode elemen hingga banyak digunakan sebagai alat bantu untuk menganalisa penelitian tersebut [1 -5]. Dalam simulasi ini, serat optik yang ditanam didalam akrilik dimodelkan memiliki kontak satu sama lain. Dalam kontak ini dapat diasumsikan berbagai koefisien kontak mulai dari tanpa gesekan samai denga nada gesekan dengan koefisien gesek tertentu. Penelitian ini bertujuan menyelidiki pengaruh koefisien gesek antara akrilik dan serat optic terhadap besarnya tegangan yang terjadi pada kedua material tersebut. Pengaruh koefisien gesek terhadap tegangan serat optic yang ditanam dalam akrilik belum pernah diteliti oleh para peneliti sebelumnya, sehingga hasil penelitian ini dapat memberikan kontribusi terhadap teknik menanamkan serat optic dalam akrilik untuk tujuan sensor tekanan.

\section{Simulasi metode elemen hingga}

$\mathrm{Bab}$ ini berisi tentang data-data penting penelitian, peralatan yang digunakan dan lokasi penelitian. Metode penelitian yang digunakan dijelaskan secara singkat (dapat dibuat dalam bentuk diagram alir). Metode baru atau metode yang dimodifikasi tersebut harap dijelaskan secara rinci.

\subsection{Model serat optik dan akrilik}

Model akrilik dan serat optic dijunjukkan pada Gambar 1. Model akrilik berupa pelat berbentuk persegi Panjang dengan Panjang $50 \mathrm{~cm}$ dan lebar $40 \mathrm{~cm}$ dan ketebalan $2 \mathrm{~mm}$. Sedangkan serat optik berupa batang solid dengan diameter $1 \mathrm{~mm}$. Pada saat simulasi, serat optic dimasukkan dalam lubang yang terletak di tengah tengah akrilik seperti terlihat pada Gambar 1 .

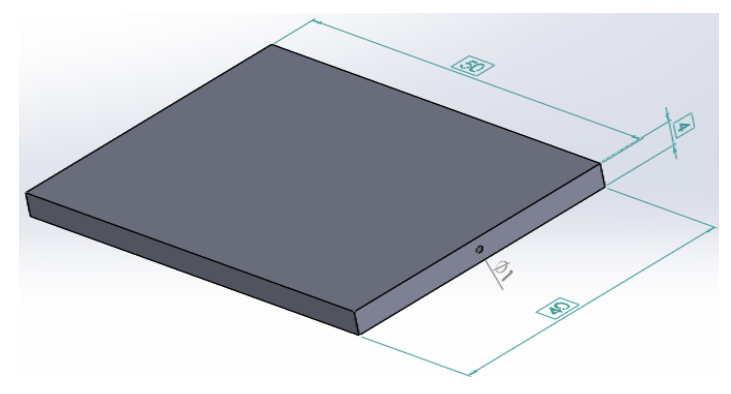

(a)

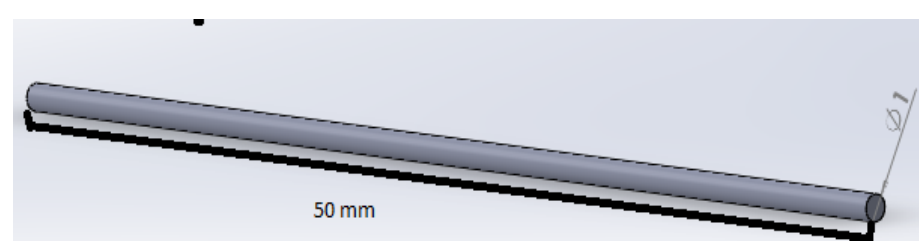

(b)

Gambar 1. Gambar Model (a) akrilik; (b) serat optik

Untuk keperluan simulasi maka diperlukan sifat sifat mekanik material, baik sifat mekanik akrilik maupun sifat mekanik serat optic. Sifat mekanik yang diperlukan adalah: modulus elastisita, poisson ratio dan massa jenis. Sifat sifat mekanik untuk kedua material yaitu serat optic dan akrilik ditunjukkan pada Table 1.

Tabel 1. Sifat sifat mekanik akrilik dan serat optik

\begin{tabular}{lcc}
\hline \multirow{2}{*}{ Mechanical Property } & \multicolumn{2}{c}{ Material } \\
\cline { 2 - 3 } & Serat Optik & 7850 \\
\hline Density $\left(\mathrm{kg} / \mathrm{m}^{3}\right)$ & 7200 & 450 \\
Ultimate Tensile Strength $(\mathrm{MPa})$ & 450 & 435 \\
Tensile Yield Strength $(\mathrm{MPa})$ & 280 & 190 \\
Modulus of Elasticity $(\mathrm{MPa})$ & 140 & 0.27 \\
Poisson's Ratio & 0.211 & \\
\hline
\end{tabular}

\subsection{Pembebanan dan kondisi batas}

Beban yang diberikan kepada serat optic dan akrilik berupa tekanan sebesar $105 \mathrm{MPa}$, dimana beban ini sebagai beban maksimum yang dapat diterima oleh akrilik dalam keadaan aman. Harga beban sebesar ini berdasarkan hasil simualsi yang telah dilakukan dengan variasi pembebanan. Beban berupa tekanan terdistribusi merata pada permukaan atas akrilik. Konfigurasi beban dan kondisi batas ditunjukkan pada Gambar 2.

Kondisi batas pada model terdiri dari dua bagian, yang pertama kondisi batas untuk akrilik dengan memberikan kondisi batas berupa tumpuan jepit (fixed support). Pada jenis kondisi batas ini, gerakan model dibatasi untuk 3 sumbu baik gerak rotasi maupun rotasi. Kondisi batas yang kedua diberikan pada kedua ujung serat optic, jenis tumpuan ini digunakan untuk membatasi gerak translasi pada arah vertical dan transversal dan membatasi gerak rotasi pada semua arah. 


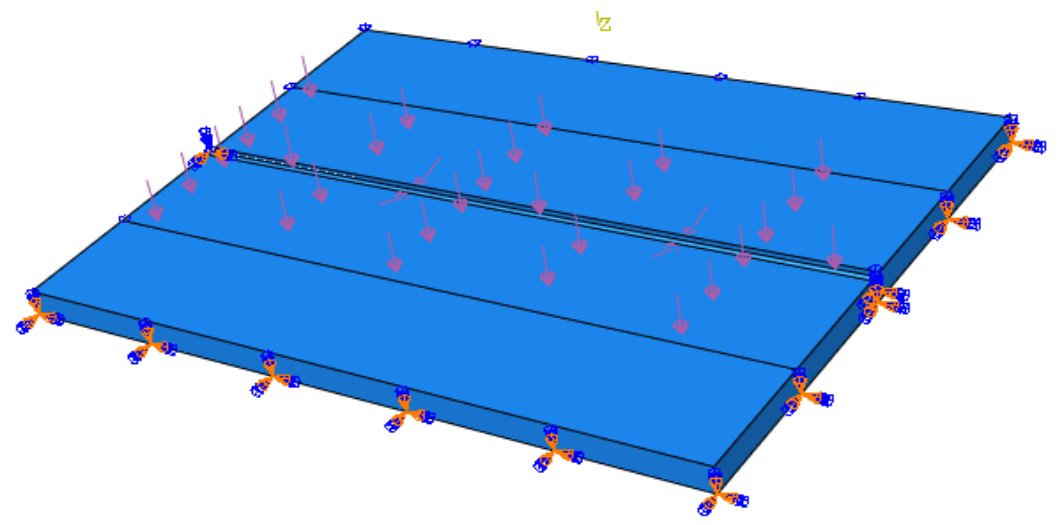

Gambar 2. Beban dan kondisi batas model

\section{Hasil dan Pembahasan}

Gambar 3 dan 5 menampilkan tegangan von Misses pada acrilik dengan beban yang sama tetapi pemodelan kontak yang berbeda. Gambar 3 menunjukkan tegangan von Misses pada akrilik dengan ketebalan 4 mm dengan kondisi kontak tanpa gesekan. Tegangan terbesar sebesar 64, $31 \mathrm{MPa}$ terjadi pada daerah kontak dengan serat optic. Berdasarkan data hasil simulasi, terlihat bahwa semakin besar koefisien gesek yang diterapkan pada kontak antara serat optik dan akrilik, maka tegangan von Misses pada akrilik akan semakin kecil.
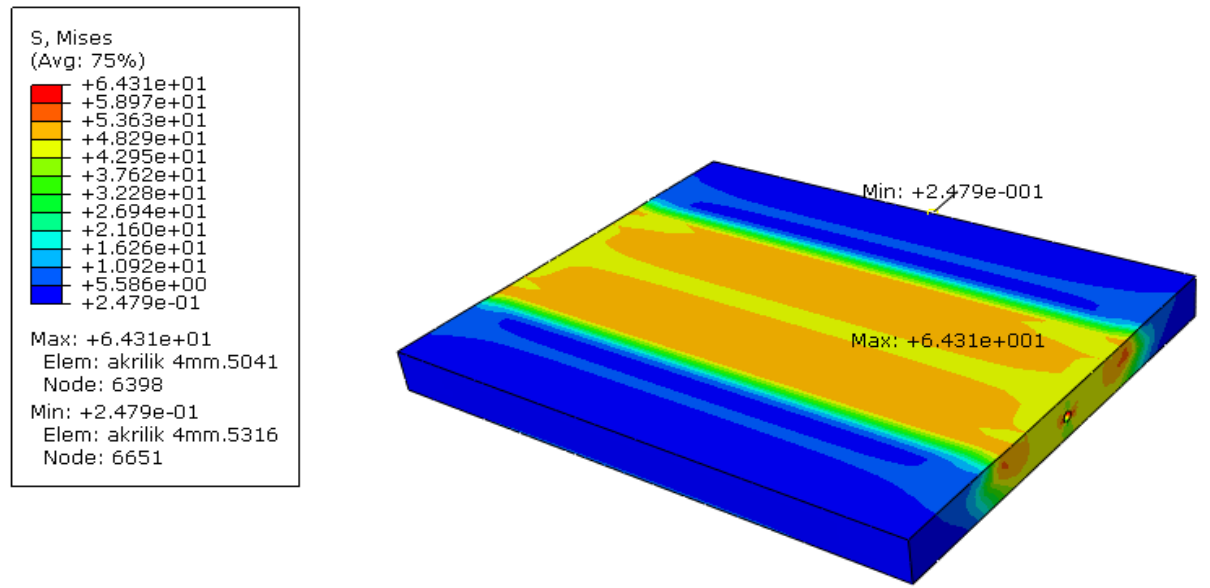

Gambar 3. Tegangan von Misses pada akrilik dengan ketebalan $4 \mathrm{~mm}$, tanpa gesekan
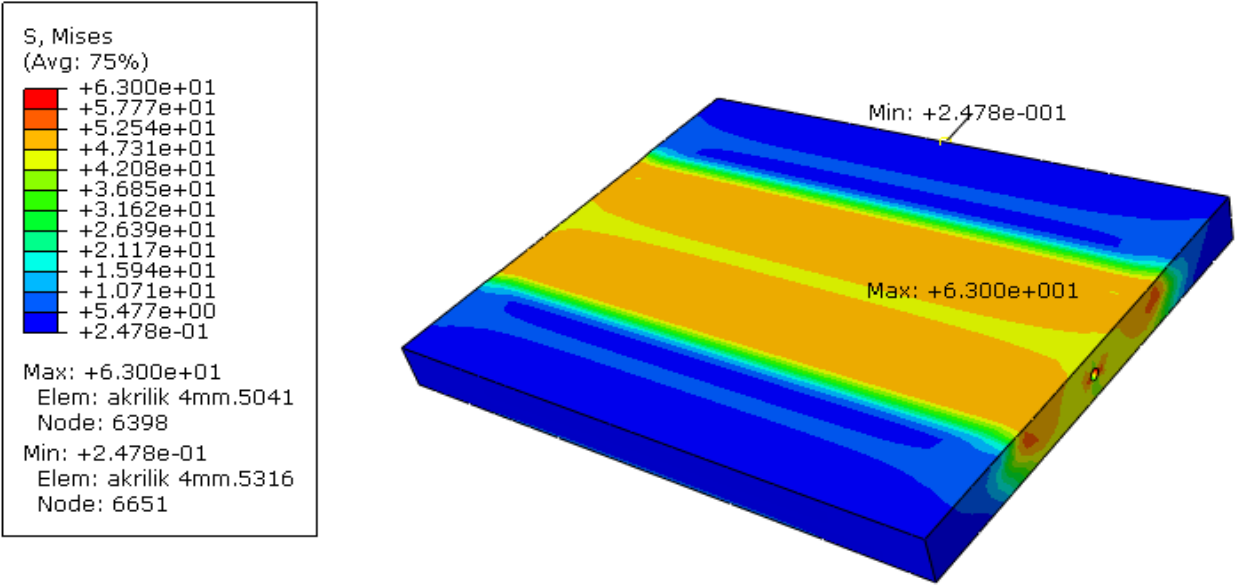

Gambar 4. Tegangan von Misses pada akrilik dengan ketebalan $4 \mathrm{~mm}$, koefisien gesek 0,3 

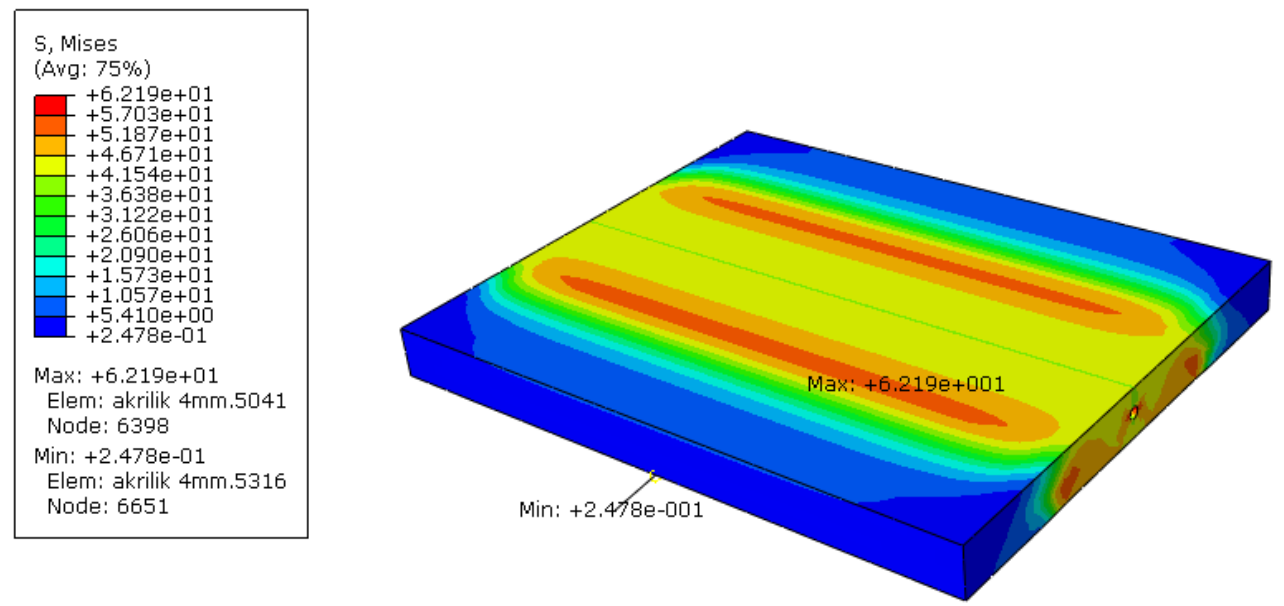

Gambar 5. Tegangan von Misses pada akrilik dengan ketebalan 4 mm, koefisien gesek 0,8
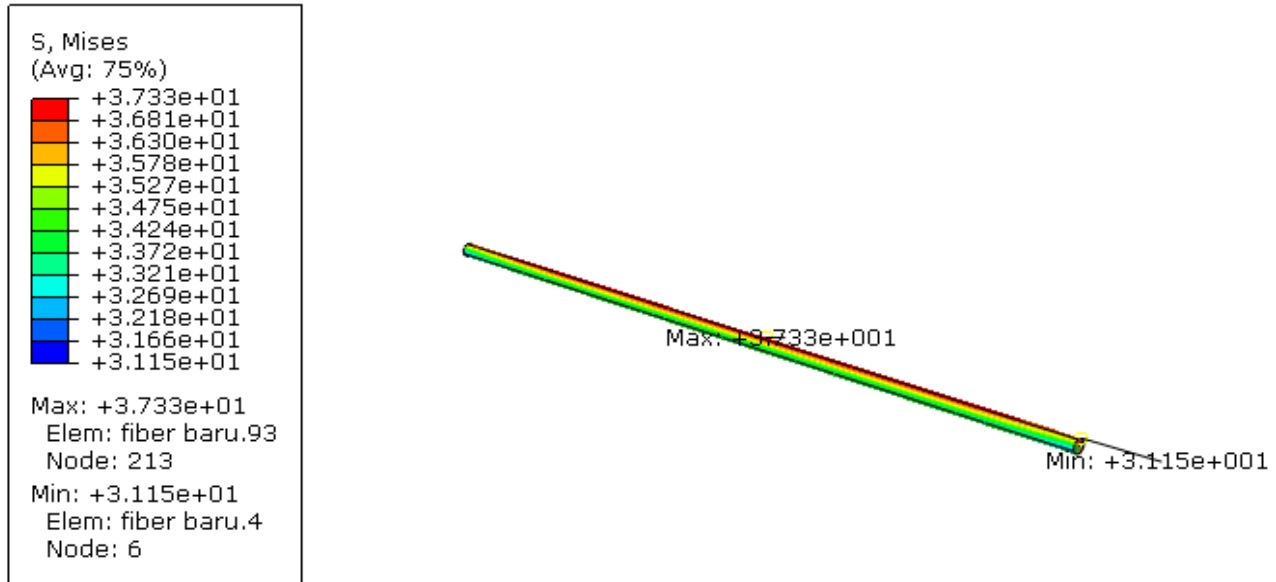

Gambar 6. Tegangan von Misses pada serat optik dengan ketebalan $4 \mathrm{~mm}$, tanpa gesekan
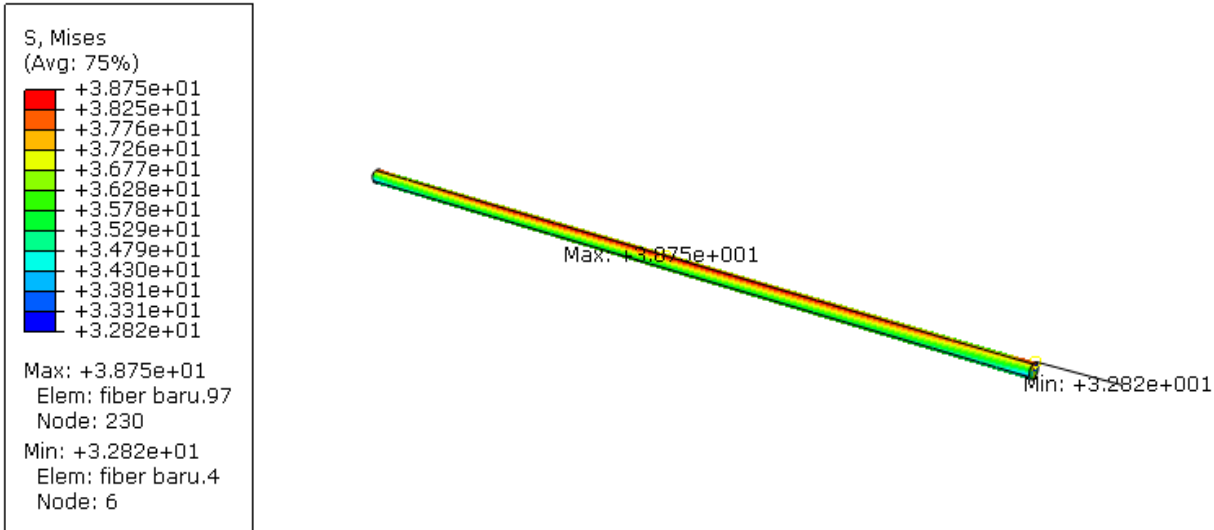

Gambar 7. Tegangan von Misses pada serat optik dengan ketebalan $4 \mathrm{~mm}$, koefisien gesek 0,3

Gambar 6 dan 8 menampilkan tegangan von Misses yang terjadi pada serat optik. Berdasarkan data hasil simulasi menunjukkan bahwa semakin besar koefisien kontak yang diterapkan pada kontak kedua material tersebut, maka tegangan von Misses-nya akan semakin besar. Jika dilihat dari segi serat optik, maka sebaiknya diberikan koefisien gesek yang serendah mungkin untuk menghasilkan tegangan yang seminimal mungkin, karena tegangan yang tinggi akan menjadi pemicu terjadinya kegagalan pada material tersebut. 

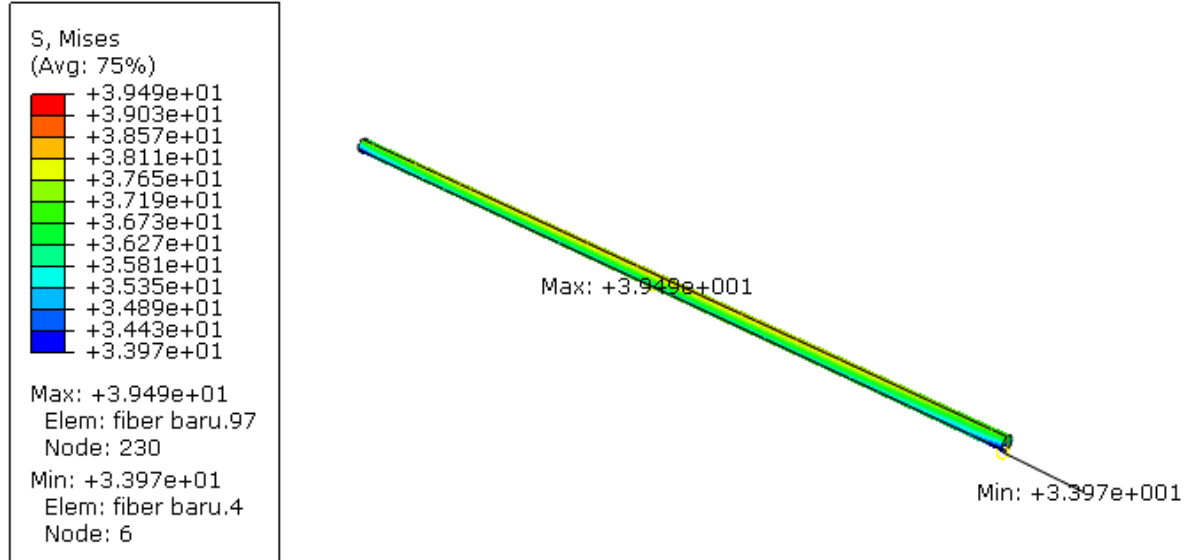

Gambar 8. Tegangan von Misses pada serat optik dengan ketebalan $4 \mathrm{~mm}$, koefisien gesek 0,8

\section{Kesimpulan}

Berdasarkan hasil simulasi pada pemodelan kontak antara serat optic dan akrilik, maka dapat disimpulkan bahwa semakin rendah koefisien gesek tegangan von Misses pada akrilik akan semakin rendah dan tegangan von Misses pada serat optic akan semakin tinggi. Hal ini terlihat kontradiktif, akan tetapi karena focus penelitian ini pada serat optiknya, maka tindakan dalam prakteknya sebaiknya memberikan koefisien gesek yang serendah mungkin. Pemodelan yang terbaik yang memberikan kondisi kontak dengan kondisi tanpa gesekan atau frictionless.

\section{Daftar Pustaka}

[1] Eaton N.C., Drew R.C., Geiger H., 1995, Finite element stress and strain 1 analysis in composites with I embedded optical fiber sensors, Smart Mater. Struct. Vol. 4, hal.113-117.

[2] Dennison C.R., Wild P.M., 2008, Enhanced sensitivity of an in-fibre Bragg grating pressure sensor achieved through fibre diameter reduction, Meas. Sci. Technol. 19, no. 12, 125301.

[3] Okamoto K., Hosaka T., Edahiro T., 1981, Stress Analysis of ptical Fibers by a Finite Element Method, Vol. 17, No. 10, hal. 2123-2129.

[4] Balać I., Milovančević M., Uskoković P., Aleksić R., 2006, Stress Field Analysis around Optical Fiber Embedded in Composite Laminae under Transverse Loading, FME Transactions, Vol. 34, hal. 53-56.

[5] Mohammad A., Hovhannes A., Sergey V., 2010, Investigation of crack propagation in single optical fiber composite with thermal influence by finite element method, Frattura ed Integrità Strutturale, Vol.13, hal. 31-35. 